BRANDÃO, Paulo de Tarso; ZANTUT, Loren Tazioli Engelbrecht. A tirania do pensamento como um dilema democrático. Revista Eletrônica Direito e Política, Programa de Pós-Graduação Stricto Sensu em Ciência Jurídica da UNIVALI, Itajaí, v.13, n.3, $3^{\circ}$ quadrimestre de 2018. Disponível em: www.univali.br/direitoepolitica - ISSN 1980-7791

\title{
CONTROLE DE CONSTITUCIONALIDADE EM AÇÃO CIVIL PÚBLICA E EM AÇÃO DIRETA DE INCONSTITUCIONALIDADE: UM DEBATE SOBRE O CONTEÚDO DOS PROVIMENTOS JURISDICIONAIS
}

\author{
CONTROL OF CONSTITUTIONALITY IN PUBLIC CIVIL ACTION AND IN DIRECT \\ ACTION OF UNCONSTITUTIONALITY: \\ A DEBATE ON THE CONTENT OF THE JUDICIAL PROCEDURES
}

Paulo de Tarso Brandão

Loren Tazioli Engelbrecht Zantut ${ }^{2}$

SUMÁRIO: Introdução; 1 Breves considerações acerca da Ação Civil Pública (ACP) e da Ação Direta De Inconstitucionalidade (ADI); 1.1 Breves considerações sobre as formas de controle de constitucionalidade no ordenamento constitucional brasileiro; 2 Teoria Geral da Norma de Pontes de Miranda e a Norma de Incidência; 3 Os efeitos da decisão na Ação Civil Pública (em face ao efeito erga omnes) e na Ação Direta De Inconstitucionalidade; Considerações finais; Referência das fontes citadas.

\section{RESUMO}

O presente artigo busca verificar a eficácia da sentença proferida em ação civil pública com pedido de inconstitucionalidade incidental e em ação direta de inconstitucionalidade, sob o prisma da teoria da norma jurídica de Pontes de Miranda. Para alcançar o resultado da pesquisa, utiliza-se levantamento bibliográfico e jurisprudencial, buscando traçar correlação teórica e prática acerca do tema. Inicialmente são traçadas breves considerações acerca da ACP e da ADI para, então, trazer à tona a Teoria Geral da Norma de Pontes de Miranda e a Norma de Incidência e, por fim, reflete-se acerca da eficácia das decisões nas ações estudadas, especificamente, na ACP, quando houver eficácia erga omnes. Palavras-chave: ação civil pública; ação direta de inconstitucionalidade; incidência da norma.

\footnotetext{
1 Mestre e Doutor em Direito pela Universidade Federal de Santa Catarina. Docente permanente do Programa de Pós-Graduação e de Graduação em Ciência Jurídica, nos Cursos de Doutorado e Mestrado, da Universidade do Vale do Itajaí - UNIVALI. Docente do Centro Educacional FACVEST (www.facvest.net). É membro da Academia Catarinense de Letras Jurídicas (ACALEJ. Procurador de Justiça no Ministério Público do Estado de Santa Catarina. E-mail: brandao@floripa.com.br

2 Mestranda bolsista PROSUP-CAPES no Programa de Pós-Graduação Stricto Sensu em Ciências Jurídicas da Universidade do Vale do Itajaí-UNIVALI - SC, Graduada em Direito e Administração pela mesma instituição, e-mail: lohengel@hotmail.com.
} 
BRANDÃO, Paulo de Tarso; ZANTUT, Loren Tazioli Engelbrecht. A tirania do pensamento como um dilema democrático. Revista Eletrônica Direito e Política, Programa de Pós-Graduação Stricto Sensu em Ciência Jurídica da UNIVALI, Itajaí, v.13, n.3, $3^{\circ}$ quadrimestre de 2018. Disponível em: www.univali.br/direitoepolitica - ISSN 1980-7791

\section{ABSTRACT}

This article seeks to verify the effectiveness of the sentence handed down in public civil action with an application for unconstitutionality and in direct action of unconstitutionality, under the prism of the legal theory of Pontes de Miranda. In order to achieve the result of the research, a bibliographical and jurisprudential survey is used, seeking to draw a theoretical and practical correlation about the theme. Initially, brief remarks are made about the ACP and ADI in order to bring to light the General Theory of the Miranda Bridges Standard and the Incidence Standard and, finally, it is reflected on the effectiveness of the decisions in the actions studied, specifically, in the ACP, where erga omnes is effective.

Keywords: public civil action; direct action of unconstitutionality; incidence of the law.

\section{INTRODUÇÃO}

Busca-se neste artigo científico analisar a eficácia da sentença proferida em ação civil pública com pedido de inconstitucionalidade incidental e em ação direta de inconstitucionalidade, sob o prisma da teoria da norma jurídica de Pontes de Miranda, englobando a linha de concentração "Direito e Jurisdição".

Para tanto, através de levantamento bibliográfico e jurisprudencial, foram traçadas breves considerações acerca da ACP e da ADI, sobre o que abordam, quais os legitimados e quais as formas de pleitear a inconstitucionalidade de leis em cada um desses instrumentos.

Após, é abordada a Teoria Geral da Norma de Pontes de Miranda e a Norma de Incidência, a fim de conceituar regra jurídica, compreender o que é o mundo e o fato para, assim, tratar da incidência da regra jurídica.

Por fim, com a base teórica já levantada, trata-se dos efeitos da decisão na ação direta de inconstitucionalidade e na ação civil pública face ao efeito erga omnes, buscando conclusão acerca do tema. Ressalte-se que esta pesquisa não busca exaurir a matéria, servindo de contribuição para posteriores reflexões sobre o assunto. 
BRANDÃO, Paulo de Tarso; ZANTUT, Loren Tazioli Engelbrecht. A tirania do pensamento como um dilema democrático. Revista Eletrônica Direito e Política, Programa de Pós-Graduação Stricto Sensu em Ciência Jurídica da UNIVALI, Itajaí, v.13, n.3, $3^{\circ}$ quadrimestre de 2018. Disponível em: www.univali.br/direitoepolitica - ISSN 1980-7791

\section{BREVES CONSIDERAÇões ACERCA DA AÇÃo CIVIL PÚBLICA (ACP) E DA AÇÃO DIRETA DE INCONSTITUCIONALIDADE (ADI)}

Com observância às leis que disciplinam o microssistema coletivo, denota-se que ação civil pública é qualquer ação movida com base na Lei no 7.347/85 - Lei da Ação Civil Pública -, para a defesa dos interesses transindividuais, seja qual for o legitimado ${ }^{3}$.

Introduzida no ordenamento jurídico brasileio pela Lei no $7.347 / 85^{4}$, encontrou na Lei no 8.078/1990, que disciplinou o Código de Defesa do Consumidor, complemento importante, uma vez que este último diploma legal, mais precisamente em seu art. 81, parágrafo único, I, II e III, esclareceu as espécies direitos ou interesses que se destina a proteger: difusos, coletivos e individuais homogêneos 5 .

Extrai-se do referido dispositivo:

Art. 81. A defesa dos interesses e direitos dos consumidores e das vítimas poderá ser exercida em juízo individualmente, ou a título coletivo.

Parágrafo único. A defesa coletiva será exercida quando se tratar de:

I - interesses ou direitos difusos, assim entendidos, para efeitos deste código, os transindividuais, de natureza indivisível, de que sejam titulares pessoas indeterminadas e ligadas por circunstâncias de fato;

II - interesses ou direitos coletivos, assim entendidos, para efeitos deste código, os transindividuais, de natureza indivisível de que seja titular grupo, categoria ou classe de pessoas ligadas entre si ou com a parte contrária por uma relação jurídica base;

\footnotetext{
3 MAZZILLI, Hugo Nigro. Defesa dos interesses difusos em juízo: meio ambiente, consumidor, patrimônio cultural, patrimônio público e outros interesses. 23. ed. São Paulo: Saraiva, 2010, p. 74

4 Art. $1^{0}$ Regem-se pelas disposições desta Lei, sem prejuízo da ação popular, as ações de responsabilidade por danos morais e patrimoniais causados: I - ao meio-ambiente; II - ao consumidor; III - a bens e direitos de valor artístico, estético, histórico, turístico e paisagístico; IV - a qualquer outro interesse difuso ou coletivo; V - por infração da ordem econômica; VI - à ordem urbanística; VII - à honra e à dignidade de grupos raciais, étnicos ou religiosos; VIII - ao patrimônio público e social.
}

5 CALDEIRA, Adriano Cesar Braz. Aspectos processuais das demandas coletivas. São Paulo: Rideel, 2006, p. 68 
BRANDÃO, Paulo de Tarso; ZANTUT, Loren Tazioli Engelbrecht. A tirania do pensamento como um dilema democrático. Revista Eletrônica Direito e Política, Programa de Pós-Graduação Stricto Sensu em Ciência Jurídica da UNIVALI, Itajaí, v.13, n.3, $3^{\circ}$ quadrimestre de 2018. Disponível em: www.univali.br/direitoepolitica - ISSN 1980-7791

III - interesses ou direitos individuais homogêneos, assim entendidos os decorrentes de origem comum ${ }^{6}$.

Os interesses difusos e coletivos estrito senso, são transindividuais. O termo transindividual, por si só, já se mostra suficiente para indicar tudo aquilo que vai além, trans + individual, aquilo que ultrapassa o indivíduo.

Assim, o campo de incidência da Ação Civil Pública é muito amplo do que aparenta o originário art. 10, da Lei 7.347/85, uma vez que o inciso IV d mesmo dispositivo determina a proteção de qualquer outro interesse difuso ou coletivo.

Para Mazzilli é equivocado entender que em ação civil pública ou coletiva somente seja possível discutir uma só espécie de direito transindividual, por não raro serem abordadas mais de uma espécie. Por exemplo, em uma única ação civil pública ou coletiva é possível combater os aumentos ilegais de mensalidades escolares já aplicados aos alunos atuais (direitos coletivos em sentido estrito), buscar repetição de indébito (interesses individuais homogêneos) e, ainda, pedir proibição de aumentos futuros (direitos difusos) ${ }^{8}$.

Essa ampliação da abrangência da Ação Civil Pública foi incluída com certo "relutar" político, como se pode observar pela evolução dos vetos incidentes sobre a expressão - "a qualquer outro interesse difuso ou coletivo"9.

\footnotetext{
${ }^{6}$ BRASIL. Lei no 8.078, de 11 de setembro de 1990. Dispõe Sobre a Proteção do Consumidor e dá Outras Providências. Brasília, DF.
}

7 CALDEIRA, Adriano Cesar Braz. Aspectos processuais das demandas coletivas. São Paulo: Rideel, 2006, p. 68

8 MAZZILLI, Hugo Nigro. Defesa dos interesses difusos em juízo: meio ambiente, consumidor, patrimônio cultural, patrimônio público e outros interesses. 23. ed. São Paulo: Saraiva, 2010, p. 52

${ }^{9} \mathrm{O}$ veto inicial, feito pelo Presidente da República da época - José Sarney -, incidiu sobre todas as menções à referida expressão (Ementa, art. 10, IV, art. $4{ }^{\circ}$ e art. 50, II) e justificou-se com a afirmação de que: "as razões de interesse público dizem respeito precipuamente a insegurança jurídica, em detrimento do bem comum, que decorre da amplíssima e imprecisa abrangência da expressão 'qualquer outro interesse difuso'".

Cinco anos depois, com a entrada em vigor do Código de Defesa do Consumidor (Lei no 8.078/90), a expressão "a qualquer outro interesse difuso ou coletivo" foi novamente incluída no texto da Lei da Ação Civil Pública.

Em 2001, o Presidente Fernando Henrique Cardoso revogou referida norma por meio da Medida Provisória no 2.180-35/01, limitando a redação do inciso IV, do art. 10, da Lei da Ação Civil Pública a "IV - a bens e direitos de valor artístico, estético, histórico, turístico e paisagístico". 
BRANDÃO, Paulo de Tarso; ZANTUT, Loren Tazioli Engelbrecht. A tirania do pensamento como um dilema democrático. Revista Eletrônica Direito e Política, Programa de Pós-Graduação Stricto Sensu em Ciência Jurídica da UNIVALI, Itajaí, v.13, n.3, $3^{\circ}$ quadrimestre de 2018. Disponível em: www.univali.br/direitoepolitica - ISSN 1980-7791

Leciona Mazzilli ${ }^{10}$ que uma análise apressada do art. 10, da Lei da Ação Civil Pública poderia dar a entender que a ação civil pública somente poderia ter por objeto a responsabilidade por danos materiais e morais a interesses transidividuais. No entanto, esta ação também pode ter por objeto pedido para evitar os danos ${ }^{11}$, pedido cominatório ${ }^{12}$ ou qualquer outro pedido para dar eficácia a tutela coletiva ${ }^{13}$.

Em sede constitucional, a ação civil pública encontra-se prescrita no art. 129, inciso III, da CRFB/8814: "São funções institucionais do Ministério Público: (...) III - promover o inquérito civil e a ação civil pública, para a proteção do patrimônio público e social, do meio ambiente e de outros interesses difusos e coletivos".

Destaca-se que os direitos individuais homogêneos não serão tema de estudo desta dissertação, por não possuírem relação com o objeto da pesquisa.

Assim, analisa-se a condenação em ação civil pública que abarca direitos difusos e coletivos, quando há o reconhecimento incidental de inconstitucionalidade de norma na decisão judicial

A ação civil pública se presta, além dos demais objetivos, para que os legitimados e, em especial o Ministério Público, tenham condições de questionar políticas públicas - o que é parte de suas atribuições o zelo -, para que os Poderes Públicos

Referida Medida Provisória, no entanto, não foi convertida em lei, razão pela qual vigora a redação trazida pelo Código de Defesa do Consumidor, possibilitando a ampliação da competência da Ação Civil Pública para resguardar qualquer interesse difuso ou coletivo.

10 MAZZILLI, Hugo Nigro. Defesa dos interesses difusos em juízo: meio ambiente, consumidor, patrimônio cultural, patrimônio público e outros interesses. 23. ed. São Paulo: Saraiva, 2010, p. 132

${ }^{11}$ Lei no 7.347/85. Art. 4o Poderá ser ajuizada ação cautelar para os fins desta Lei, objetivando, inclusive, evitar dano ao patrimônio público e social, ao meio ambiente, ao consumidor, à honra e à dignidade de grupos raciais, étnicos ou religiosos, à ordem urbanística ou aos bens e direitos de valor artístico, estético, histórico, turístico e paisagístico.

12 Lei no 7.347/85. Art. $3^{\circ}$ A ação civil poderá ter por objeto a condenação em dinheiro ou 0 cumprimento de obrigação de fazer ou não fazer.

13 Lei no 7.347/85. Art. 21. Aplicam-se à defesa dos direitos e interesses difusos, coletivos e individuais, no que for cabível, os dispositivos do Título III da lei que instituiu o Código de Defesa do Consumidor. Lei no 8.078/90 Art. 83. Para a defesa dos direitos e interesses protegidos por este código são admissíveis todas as espécies de ações capazes de propiciar sua adequada e efetiva tutela. Lei no Art. 90. Aplicam-se às ações previstas neste título as normas do Código de Processo Civil e da Lei n 7.347, de 24 de julho de 1985 [atualmente o CPC/15], inclusive no que respeita ao inquérito civil, naquilo que não contrariar suas disposições.

14 BRASIL. Constituição da República Federativa do Brasil (1988), de 05 de outubro de 1988. 
BRANDÃO, Paulo de Tarso; ZANTUT, Loren Tazioli Engelbrecht. A tirania do pensamento como um dilema democrático. Revista Eletrônica Direito e Política, Programa de Pós-Graduação Stricto Sensu em Ciência Jurídica da UNIVALI, Itajaí, v.13, n.3, $3^{\circ}$ quadrimestre de 2018. Disponível em: www.univali.br/direitoepolitica - ISSN 1980-7791

e os serviços de relevância pública observem os direitos assegurados pela Constituição da República Federativa do Brasil. Sobre essa possibilidade e limites, afirma Mazzilli:

Com certeza, não poderá o Ministério Público pedir ao Judiciário que administre no lugar do administrador; contudo, poderá cobrar em juízo a aplicação dos princípios da Administração que possam estar sendo descurados, e, com isso, restaurar a legalidade.

Também não poderá o Ministério Público estar movido por critérios político-partidários; entretanto, sua ação tem inegável caráter político, no sentido técnico da expressão ${ }^{15}$.

Deste modo, conclui-se que os legitimados para propor Ação Civil Pública têm respaldo legal para questionar atos do governo, que, entre outras hipóteses, ferirem o princípio da legalidade, moralidade, eficiência ou configurarem abuso de poder $^{16}$. Entre esses questionamentos pode estar também ato que fira dispositivo constitucional demandando decisão sobre a validade do ato diante de eventual vício de constitucionalidade.

Desta maneira, no ordenamento jurídico brasileiro, todos os direitos de grupos, classes ou categorias de pessoas merecem acesso à Justiça através da tutela coletiva, não bastando apenas a possibilidade da individual ${ }^{17}$. Esse acesso à Justiça por meio da tutela coletiva é exercido pelas ações coletivas e tem as seguintes características:

Nos conflitos difusos o objeto da lide são interesses difusos, coletivos ou individuais homogêneos, além de abarcar interesses macrossociais - grupos, categorias ou classes de pessoas com pretensões colidentes entre $\mathrm{si}^{18}$.

\footnotetext{
15 MAZZILLI, Hugo Nigro. Defesa dos interesses difusos em juízo: meio ambiente, consumidor, patrimônio cultural, patrimônio público e outros interesses. 23. ed. São Paulo: Saraiva, 2010, p. 133

16 MAZZILLI, Hugo Nigro. Defesa dos interesses difusos em juízo: meio ambiente, consumidor, patrimônio cultural, patrimônio público e outros interesses. 23. ed. São Paulo: Saraiva, 2010, p. 133

17 MAZZILLI, Hugo Nigro. Defesa dos interesses difusos em juízo: meio ambiente, consumidor, patrimônio cultural, patrimônio público e outros interesses. 23. ed. São Paulo: Saraiva, 2010, p. 51

18 MAZZILLI, Hugo Nigro. Defesa dos interesses difusos em juízo: meio ambiente, consumidor, patrimônio cultural, patrimônio público e outros interesses. 23. ed. São Paulo: Saraiva, 2010, p. 51
} 
BRANDÃO, Paulo de Tarso; ZANTUT, Loren Tazioli Engelbrecht. A tirania do pensamento como um dilema democrático. Revista Eletrônica Direito e Política, Programa de Pós-Graduação Stricto Sensu em Ciência Jurídica da UNIVALI, Itajaí, v.13, n.3, $3^{\circ}$ quadrimestre de 2018. Disponível em: www.univali.br/direitoepolitica - ISSN 1980-7791

Parte da doutrina, tal como a de Mazzilli, entende que a defesa judicial coletiva se faz por meio de legitimação extraordinária, ou seja, o autor da ação coletiva defende direitos individuais alheios, não raros até mesmo disponíveis, compartilhados por grupo, classe ou categoria de pessoas ${ }^{19}$.

No entanto, parte da doutrina, ainda que minoritária, como defendido por Brandão, entende que a defesa judicial coletiva se faz por meio de legitimação ordinária, por decorrer de lei, como se explica a seguir:

Em síntese, a legitimidade para buscar em Juízo a tutela dos interesses coletivos (abrangendo com tal expressão os interesses coletivos, difusos e individuais homogêneos) decorre de lei. Assim, na esfera da Ação Civil Pública não opera o conceito ou a noção de legitimidade extraordinária, uma vez que as pessoas jurídicas ou as instituições são legitimadas por força de disposição legal; e, nesse caso, a legitimação é sempre ordinária. Qualquer outra pessoa que não seja legitimada por força de lei não poderá exercitar o direito de ação decorrente da Ação Civil Pública, pois em nenhuma hipótese poderá haver a substituição processual, ou seja, a legitimação extraordinária ${ }^{20}$.

Sendo mais preciso pode-se dizer que a legitimidade é mesmo legal e não propriamente ordinária. Somente há razão para falar em legitimação ordinária no contraponto com a legitimação extraordinária. Não existido esta possibilidade bastaria simplesmente falar-se em legitimação, sem adjetivação. De qualquer forma, como ainda no senso comum há confusão entre estes conceitos, melhor é utilizar a adjetivação diferenciadora e correta e falar em legitimação legal.

Existe, ainda, uma terceira corrente, preconizada por Nelson Nery Jr. e Rosa Maria de Andrade Nery, que defende ser a legitimação das ações coletivas divididas em: i) extraordinária, quando versar sobre direitos individuais homogêneos; e ii) autônoma, quanto tratar de direitos difusos ou coletivos. Explicam os autores:

\footnotetext{
19 MAZZILLI, Hugo Nigro. Defesa dos interesses difusos em juízo: meio ambiente, consumidor, patrimônio cultural, patrimônio público e outros interesses. 23. ed. São Paulo: Saraiva, 2010, p. 51 e 52

20 BRANDÃO, Paulo de Tarso. Ações Constitucionais: "Novos" Direitos e Acesso à Justiça. 2. ed. Florianópolis: Oab/sc, 2006, p. 231
} 
BRANDÃO, Paulo de Tarso; ZANTUT, Loren Tazioli Engelbrecht. A tirania do pensamento como um dilema democrático. Revista Eletrônica Direito e Política, Programa de Pós-Graduação Stricto Sensu em Ciência Jurídica da UNIVALI, Itajaí, v.13, n.3, $3^{\circ}$ quadrimestre de 2018. Disponível em: www.univali.br/direitoepolitica - ISSN 1980-7791

\section{A figura da substituição processual pertence exclusivamente ao direito singular, e, no âmbito processual, ao direito processual civil individual. Só tem sentido falar-se em substituição processual diante da discussão sobre um direito subjetivo (singular), objeto da substituição: o substituto substitui pessoa determinada, defendendo em seu nome $o$ direito alheio do substituído.}

Os direitos difusos e coletivos não podem ser regidos pelo mesmo sistema, justamente porque têm como característica a não individualidade. Não se pode substituir coletividade ou pessoas indeterminadas. O fenômeno é outro, próprio do direito processual coletivo. (...) Por essa legitimação autônoma para condução do processo, o legislador, independentemente do conteúdo do direito material a ser discutido em juízo, legitima pessoa, órgão ou entidade a conduzir o processo judicial no qual se pretende proteger o direito difuso ou coletivo ${ }^{21}$. (Grifou-se)

Resumindo, que a Ação Civil Pública é a demanda judicial regulada pela Lei $7.345 / 85$, e que permite os legitimados proteger interesses difusos e coletivos.

Para o debate a que se propõe o trabalho é importante lembrar que em razão da natureza dos interesses defendidos na Ação Civil Pública, especialmente os difusos e coletivos stricto sensu, a sentença terá efeito erga omnes, ou seja, terá validade em relação a todos os que se encontram na situação jurídica reconhecida na sentença. Esse efeito quando unido a uma questão incidental de (in)constitucionalidade, atinge outro patamar de complexidade. A complexidade se dá porque havendo o debate incidente sobre constitucionalidade o juiz julgará com base no controle difuso de constitucionalidade e sua sentença terá (ou poderá ter) efeito erga omnes.

A Ação Direta Inconstitucionalidade 22 , por sua vez, tem como finalidade específica tratar do controle de constitucionalidade de leis e atos normativos. Ou seja, a Ação

21 NERY JR., Nelson; NERY, Rosa Maria de Andrade. Código de processo civil comentado e legislação extravagante. $14^{a}$ ed., São Paulo: Editora Revista dos Tribunais, 2014, p. 230-231.

22 No Supremo Tribunal Federal, essa ação é representada pela sigla ADI. BRASIL. SUPREMO TRIBUNAL FEDERAL. Glossário Jurídico: Ação Direta de Inconstitucionalidade. 2018. Disponível em: <http://www.stf.jus.br/portal/glossario/>. Acesso em: 15 dez. 2018. 
BRANDÃO, Paulo de Tarso; ZANTUT, Loren Tazioli Engelbrecht. A tirania do pensamento como um dilema democrático. Revista Eletrônica Direito e Política, Programa de Pós-Graduação Stricto Sensu em Ciência Jurídica da UNIVALI, Itajaí, v.13, n.3, $3^{\circ}$ quadrimestre de 2018. Disponível em: www.univali.br/direitoepolitica - ISSN 1980-7791

Direta de Inconstitucionalidade é instrumento que visa verificar e controlar a compatibilidade o ordenamento jurídico com a ordem constitucional.

A adi tem seu fundamento extraído da Constituição Federal (CRFB/88), especificamente no art. 102, I, "a"23 das Constituições Estaduais nas hipóteses que a competência seja dos Tribunais de Justiça por seu órgão pleno ${ }^{24}$. Para regulamentar referida ação, o legislador infraconstitucional prescrever os arts 20 a 12 da Lei $9868 / 1999^{25}$ e, por fim, no próprio órgão julgador, o STF, foi regulado pelos arts. 101 e 169 a 178 do RISTF${ }^{26}$.

Os legitimados para propor ADI encontram-se no art. 103, da CRFB/88 ${ }^{27}$, constando dentre eles o Presidente da República, a Mesa do Senado Federal, da Câmara dos Deputados e de Assembleia Legislativa ou da Câmara Legislativa do Distrito Federal, o Governador de Estado ou do Distrito Federal, o Procurador-Geral da República; o Conselho Federal da $O A B$, partido político com representação no Congresso Nacional e confederação sindical ou entidade de classe de âmbito nacional. No âmbito dos Estados os legitimados estão regulados nas diversas constituições estaduais, como por exemplo, no art. 85 da Constituição de SC28.

23 CRFB/88. Art. 102. Compete ao Supremo Tribunal Federal, precipuamente, a guarda da Constituição, cabendo-lhe: I - processar e julgar, originariamente: a) a ação direta de inconstitucionalidade de lei ou ato normativo federal ou estadual e a ação declaratória de constitucionalidade de lei ou ato normativo federal;

${ }^{24}$ A exemplo em Santa Catarina: SANTA CATARINA. Constituição Estadual de Santa Catarina. Art. 83. Compete privativamente ao Tribunal de Justiça: XI - processar e julgar, originariamente: f) as ações diretas de inconstitucionalidade de leis ou atos normativos estaduais e municipais contestados em face desta Constituição;

25 BRASIL. Lei no 9868/1999, de 10 de novembro de 1999. Dispõe sobre o processo e julgamento da ação direta de inconstitucionalidade e da ação declaratória de constitucionalidade perante o Supremo Tribunal Federal. Brasília, DF, 10 nov. 1999.

26 Regimento Interno do Supremo Tribunal Federal. Art. 101. A declaração de constitucionalidade ou inconstitucionalidade de lei ou ato normativo, pronunciada por maioria qualificada, aplica-se aos novos

feitos submetidos às Turmas ou ao Plenário, salvo o disposto no art. 103. [...] Título VI: Da Declaração de Inconstitucionalidade e da Interpretação de Lei.

27 BRASIL. Constituição da República Federativa do Brasil (1988), de 05 de outubro de 1988.

${ }^{28}$ SANTA CATARINA. Constituição Estadual de Santa Catarina. Art. 85. São partes legítimas para propor a ação direta de inconstitucionalidade de lei ou ato normativo estadual ou municipal contestado em face desta Constituição: I - o Governador do Estado; II - a Mesa da Assembleia Legislativa ou um quarto dos Deputados Estaduais; III - o Procurador-Geral de Justiça; IV - o Conselho Secional da Ordem dos Advogados do Brasil; V - os partidos políticos com representação na Assembleia Legislativa; VI - as federações sindicais e as entidades de classe de âmbito estadual; 
BRANDÃO, Paulo de Tarso; ZANTUT, Loren Tazioli Engelbrecht. A tirania do pensamento como um dilema democrático. Revista Eletrônica Direito e Política, Programa de Pós-Graduação Stricto Sensu em Ciência Jurídica da UNIVALI, Itajaí, v.13, n.3, $3^{\circ}$ quadrimestre de 2018. Disponível em: www.univali.br/direitoepolitica - ISSN 1980-7791

\subsection{BREVES CONSIDERAÇÕES SOBRE AS FORMAS DE CONTROLE DE CONSTITUCIONALIDADE NO ORDENAMENTO CONSTITUCIONAL BRASILEIRO}

Várias são as formas de controlar-se a constitucionalidade das leis e atos normativos no sistema constitucional brasileiro, a saber:

i) de controle preventivo de constitucionalidade, feito pelo legislativo (Comissões de Constituição e Justiça) e pelo executivo (veto jurídico ${ }^{29}$ ); e ii) Repressivo, realizado, em regra: a) pelo Judiciário, sendo dividido em controle difuso ou por via de exceção ou defesa (art. 97, da CRFB $/ 88^{30}$ ) e controle concentrado, que é exercido em regra via $A D I^{31}, A D I$ por Omissão ${ }^{32}, A D I$ Interventiva ${ }^{33}, A D C^{34} \mathrm{e}$

VII - o Prefeito, a Mesa da Câmara ou um quarto dos Vereadores, o representante do Ministério Público, a subseção da Ordem dos Advogados do Brasil, os sindicatos e as associações representativas de classe ou da comunidade, quando se tratar de lei ou ato normativo municipal. (Redação dada pela EC/45, de 2006).

${ }^{29}$ CRFB/88. Art. 66. A Casa na qual tenha sido concluída a votação enviará o projeto de lei ao Presidente da República, que, aquiescendo, o sancionará. § $1 \mathbf{0}$ Se o Presidente da República considerar o projeto, no todo ou em parte, inconstitucional ou contrário ao interesse público, vetálo-á total ou parcialmente, no prazo de quinze dias úteis, contados da data do recebimento, e comunicará, dentro de quarenta e oito horas, ao Presidente do Senado Federal os motivos do veto.

30 CRFB/88. Art. 97. Somente pelo voto da maioria absoluta de seus membros ou dos membros do respectivo órgão especial poderão os tribunais declarar a inconstitucionalidade de lei ou ato normativo do Poder Público.

31 Ação Direta de Inconstitucionalidade. CRFB/88. Art. 102. Compete ao Supremo Tribunal Federal, precipuamente, a guarda da Constituição, cabendo-lhe: I - processar e julgar, originariamente: a) a ação direta de inconstitucionalidade de lei ou ato normativo federal ou estadual e a ação declaratória de constitucionalidade de lei ou ato normativo federal

32 Ação Direta de Inconstitucionalidade por Omissão. CRFB/88. Art. 103. § 20 Declarada a inconstitucionalidade por omissão de medida para tornar efetiva norma constitucional, será dada ciência ao Poder competente para a adoção das providências necessárias e, em se tratando de órgão administrativo, para fazê-lo em trinta dias.

33 Ação Direta de Inconstitucionalidade Interventiva. CRFB/88. Art. 36. A decretação da intervenção dependerá: III - de provimento, pelo Supremo Tribunal Federal, de representação do Procurador-Geral da República, na hipótese do art. 34, VII, e no caso de recusa à execução de lei federal.

34 Ação Declaratória de Constitucionalidade. CRFB/88. Art. 102. Compete ao Supremo Tribunal Federal, precipuamente, a guarda da Constituição, cabendo-lhe: I - processar e julgar, originariamente: a) a ação direta de inconstitucionalidade de lei ou ato normativo federal ou estadual e a ação declaratória de constitucionalidade de lei ou ato normativo federal 
BRANDÃO, Paulo de Tarso; ZANTUT, Loren Tazioli Engelbrecht. A tirania do pensamento como um dilema democrático. Revista Eletrônica Direito e Política, Programa de Pós-Graduação Stricto Sensu em Ciência Jurídica da UNIVALI, Itajaí, v.13, n.3, $3^{\circ}$ quadrimestre de 2018. Disponível em: www.univali.br/direitoepolitica - ISSN 1980-7791

$\operatorname{ADPF}^{35}$ e, excepcionalmente; b) pelo Legislativo, por Medidas Provisórias ${ }^{36}$ ou por delegação ${ }^{37}$.

Interessa ao âmbito deste trabalho o controle repressivo feito pelo Judiciário, que, como dito acima, divide-se em controle concentrado e difuso, uma vez que no Brasil o controle de constitucionalidade repressivo é misto (difuso ou concentrado) $)^{38}$.

O controle difuso ${ }^{39}$, o art. 97 da CRFB/88 confere competência para a análise da constitucionalidade das normas em concreto por todo e qualquer juiz, sendo ele de Primeiro Grau, dos Tribunais ou das Cortes Supremas - STF ${ }^{40}$ E STJ ${ }^{41}$.

35 Ação de Descumprimento de Preceito Fundamental. CRFB/88. Art. 102. § 10 A arguição de descumprimento de preceito fundamental, decorrente desta Constituição, será apreciada pelo Supremo Tribunal Federal, na forma da lei.

36 CRFB/88. Art. 62. \$ $5^{\circ}$ A deliberação de cada uma das Casas do Congresso Nacional sobre o mérito das medidas provisórias dependerá de juízo prévio sobre o atendimento de seus pressupostos constitucionais.

37 CRFB/88. Art. 49. É da competência exclusiva do Congresso Nacional: V - sustar os atos normativos do Poder Executivo que exorbitem do poder regulamentar ou dos limites de delegação legislativa; 732.

38 MORAES, Alexandre de. Direito Constitucional. 30. ed. São Paulo: Editora Atlas S.a., 2014. p.

39 O controle normativo de constitucionalidade qualifica-se como típico processo de caráter objetivo, vocacionado, exclusivamente, à defesa, em tese, da harmonia do sistema constitucional. A instauração desse processo objetivo tem por função instrumental viabilizar o julgamento da validade abstrata do ato estatal em face da Constituição da República. O exame de relações jurídicas concretas e individuais constitui matéria juridicamente estranha ao domínio do processo de controle concentrado de constitucionalidade. A tutela jurisdicional de situações individuais, uma vez suscitada a controvérsia de índole constitucional, há de ser obtida na via do controle difuso de constitucionalidade, que, supondo a existência de um caso concreto, revela-se acessível a qualquer pessoa que disponha de interesse e legitimidade. ADI 2.551 MC-QO, rel. min. Celso de Mello, j. 2-4-2003, P, DJ de 20-4-2006.

40 O STF exerce, por excelência, o controle difuso de constitucionalidade quando do julgamento do recurso extraordinário, tendo os seus colegiados fracionários competência regimental para fazê-lo sem ofensa ao art. 97 da CF. RE 361.829 ED, rel. min. Ellen Gracie, j. 2-3-2010, 2a T, DJE de 193-2010.

41 O STJ, ao negar seguimento ao recurso especial com fundamento constitucional, exerceu o chamado controle difuso de constitucionalidade, que é possibilitado a todos os órgãos judiciais indistintamente. [...] Rcl 8.163 AgR, rel. min. Ricardo Lewandowski, j. 3-11-2011, P, DJE de 28$11-2011$

O STJ, uma vez ultrapassada a barreira de conhecimento do recurso especial, julga a lide, cabendoIhe, como ocorre em relação a todo e qualquer órgão investido do ofício judicante, o controle difuso de constitucionalidade. (...) Deixando o órgão de examinar questão versada pela parte, isso após conhecido recurso com o qual se defrontou, verifica-se o vício de procedimento e, portanto, a abertura de via à arguição pertinente. AI 217.753 AgR, rel. min. Marco Aurélio, j. 10-12-1998, $2^{\mathrm{a}} \mathrm{T}$, DJ de 23-4-1999. = Rcl 6.882 AgR, rel. min. Cármen Lúcia, j. 24-3-2011, P, DJE de 12-4-2011 
BRANDÃO, Paulo de Tarso; ZANTUT, Loren Tazioli Engelbrecht. A tirania do pensamento como um dilema democrático. Revista Eletrônica Direito e Política, Programa de Pós-Graduação Stricto Sensu em Ciência Jurídica da UNIVALI, Itajaí, v.13, n.3, $3^{\circ}$ quadrimestre de 2018. Disponível em: www.univali.br/direitoepolitica - ISSN 1980-7791

O controle difuso de constitucionalidade nasceu nos Estados Unidos da América, com o caso Madison vs Marbury, relatado pelo juiz Marshall em fevereiro de 1803, o que inspirou outros sistemas jurídicos a criar instrumentos próprios com a mesma finalidade. Este caso foi o primeiro em que a Suprema Corte Norte Americana decidiu que era o Poder competente para invalidar a lei inconstitucional, ainda que o Judiciário não tivesse características legislativas ${ }^{42}$. Sobre o caso:

O controle de constitucionalidade surgiu nos Estados Unidos, sob uma Constituição que não o prevê expressamente. Todavia pôde Marshall, em decisão célebre, deduzir de seu sistema esse controle e reconhecer pertencer ele ao Judiciário, incumbido de aplicar a lei contenciosamente.

No caso Marbury versus Madison, esse juiz demonstrou que, se a Constituição americana era a base do direito e imutável por meios ordinários, as leis comuns que a contradissessem não eram verdadeiramente leis, não eram direito. Assim, as leis seriam nulas, não obrigando os particulares. Demonstrou mais que, cabendo ao judiciário dizer o que é o direito, é a ele que compete indagar a constitucionalidade de uma $\operatorname{lei}^{43}$.

Importante distinção do controle concentrado do difuso é que neste último o Judiciário se manifesta acerca da (in)constitucionalidade não se trata do objeto principal da lide, mas sim sobre questão prévia, indispensável para julgar o mérito ${ }^{44}$.

No ordenamento jurídico brasileiro, a possibilidade de exercer controle difuso existe desde a Constituição de 1891, segunda Constituição do país, também chamada de Constituição Republicana ${ }^{45}$ e foi criado pela influência de Ruy Barbosa.

42 BRASIL. SUPREMO TRIBUnAL FEDERAL. Notícias do STF: Ministro Joaquim Barbosa é o convidado do programa Aula Magna, com exibição às 21h. 2003. Disponível em: <http://noticias.stf.jus.br/portal/cms/verNoticiaDetalhe.asp?idConteudo=61802>. Acesso em: 15 dez. 2018.

43 FERREIRA FILHO, Manoel Gonçalves. Curso de direito constitucional. 37a ed. São Pualo: Saraiva, 2011. p. 60

44 MORAES, Alexandre de. Direito Constitucional. 30. ed. São Paulo: Editora Atlas S.a., 2014. p. 733.

45 Constituição da República dos Estados Unidos do Brasil de 1981. Art. 59. § $1^{\circ}$ (redação do texto originário, revogado em 1926 pela EC no 03/26). Das sentenças das Justiças dos Estados, em última instância, haverá recurso para o Supremo Tribunal Federal: a) quando se questionar sobre a validade, ou a aplicação de tratados e leis federais, e a decisão do Tribunal do Estado for contra ela; b) quando se contestar a validade de leis ou de atos dos Governos dos Estados 
BRANDÃO, Paulo de Tarso; ZANTUT, Loren Tazioli Engelbrecht. A tirania do pensamento como um dilema democrático. Revista Eletrônica Direito e Política, Programa de Pós-Graduação Stricto Sensu em Ciência Jurídica da UNIVALI, Itajaí, v.13, n.3, $3^{\circ}$ quadrimestre de 2018. Disponível em: www.univali.br/direitoepolitica - ISSN 1980-7791

A principal característica do controle judicial difuso é a de que somente é possível exerce-lo perante um caso concreto, ou seja, é pedido incidente e não mérito principal $^{46}$.

O controle concentrado é exercido pelo Supremo Tribunal Federal que tem competência originária para declarar a inconstitucionalidade de uma lei ou ato normativo federal ou estadual, quando a arguição tenha como parâmetro a Constituição Federal; ou pelos Tribunais Plenos do Tribunais de Justiça dos Estados quando o questionamento da inconstitucionalidade for de lei ou ato normativo estadual ou municipal em face da Constituição do Estado Federado. Nessa espécie de ação o julgamento tem por objeto a norma em abstrato, sem avaliar sua aplicação a um caso concreto, sendo a legitimidade ativa para propor ADI prevista no art. 103 da $\mathrm{CF}^{47}$.

Em suma, as ações ora analisadas têm finalidade distintas, mas em ambas é possível exercer controle de constitucionalidade, porém de formas diversas. $\mathrm{Na}$ Ação Civil Pública cabe o controle difuso e na Ação Direta de Inconstitucionalidade o controle concentrado. Em razão do caráter erga omnes da sentença na Ação Civil Pública há uma certa incompreensão decorrente de duas ordens: a primeira o tratado da Ação Civil Pública como ação típica de processo civil; a segunda sobre a natureza jurídica da decisão que julga a inconstitucionalidade em uma e outra ação.

A primeira das incompreensões já foi objeto de estudo em outros trabalhos ${ }^{48}$ e a segunda é o objeto do presente trabalho.

em face da Constituição, ou das leis federais, e a decisão do Tribunal do Estado considerar válidos esses atos, ou essas leis impugnadas.

46 MORAES, Alexandre de. Direito Constitucional. 30. ed. São Paulo: Editora Atlas S.A., 2014. p. 735.

47 BRASIL. SUPREMO TRIBUNAL FEDERAL. Glossário Jurídico: Ação Direta de Inconstitucionalidade. 2018. Disponível em: <http://www.stf.jus.br/portal/glossario/>. Acesso em: 15 dez. 2018.

48 V. BRANDÃO, Paulo de Tarso. Ação Civil Pública. Florianópolis: Obra Jurídica, 1998; BRANDÃO, Paulo de Tarso. Ações Constitucionais: "Novos" Direitos e Acesso à Justiça. 2. ed. Florianópolis: OAB/SC, 2006. 
BRANDÃO, Paulo de Tarso; ZANTUT, Loren Tazioli Engelbrecht. A tirania do pensamento como um dilema democrático. Revista Eletrônica Direito e Política, Programa de Pós-Graduação Stricto Sensu em Ciência Jurídica da UNIVALI, Itajaí, v.13, n.3, $3^{\circ}$ quadrimestre de 2018. Disponível em: www.univali.br/direitoepolitica - ISSN 1980-7791

Analisa-se a seguir a teoria geral da norma, teoria formulada por Pontes de Miranda, para buscar esclarecer quais os efeitos da decisão na ADI e na ACP, com efeito erga omnes.

\section{TEORIA GeRAL DA NORMA DE PONTES DE MIRANDA E A NORMA DE INCIDÊNCIA}

Para tratar da eficácia das decisões em Ação Civil Pública na qual ocorra o reconhecimento incidente de inconstitucionalidade de lei ou ato normativo na via difusa e na Ação Direta de Inconstitucionalidade que é concebida exatamente para a arguição de inconstitucionalidade na forma concentrada, útil será entender o que Pontes de Miranda denominou relação de incidência da norma sobre o suporte fático, que adjetivou de suficiente.

Para Pontes de Miranda ${ }^{49}$ expõe em sua obra Tratado de Direito Privado sua teoria acerca da incidência da norma no mundo dos fatos. Para iniciar seus argumentos, conceitua regra jurídica e suporte fático:

1. Regra e suporte fático. A regra é norma com que o homem, ao querer subordinar os fatos a certa ordem e a certa previsibilidade, procurou distribuir os bens da vida. Há o fato de legislar, que é edictar a regra jurídica; há o fato de existir, despregada do legislador, a regra jurídica; há o fato de incidir, sempre que ocorra o que ela prevê e regula. O que é por ela previsto e sobre o qual ela incide é o suporte fático, conceito da mais alta relevância para as exposições e as investigações científicas. No trato do direito já feito, da lex lata, - já transposta, portanto, a linha para aquém da qual ficou a técnica legislativa e o fato de legislar $[\ldots]^{50}$.

Pontes de Miranda conclui que o que interessa na teoria por ele formulada é o fato da regra jurídica, o fato de se comporem suportes fáticos e o fato da incidência,

\footnotetext{
49 MIRANDA, Pontes de. Tratado de direito privado - Tomo I (vol. 1). Introdução Pessoas Físicas e Jurídicas. $2^{a}$ ed. Campinas: Bookseller, 2000. p. 49/50.

50 MIRANDA, Pontes de. Tratado de direito privado - Tomo I (vol. 1). Introdução Pessoas Físicas e Jurídicas. $2^{\mathrm{a}}$ ed. Campinas: Bookseller, 2000. p. 49.
} 
BRANDÃO, Paulo de Tarso; ZANTUT, Loren Tazioli Engelbrecht. A tirania do pensamento como um dilema democrático. Revista Eletrônica Direito e Política, Programa de Pós-Graduação Stricto Sensu em Ciência Jurídica da UNIVALI, Itajaí, v.13, n.3, $3^{\circ}$ quadrimestre de 2018. Disponível em: www.univali.br/direitoepolitica - ISSN 1980-7791

para, com isso, tratar os problemas do direito como físico, isto é, vê-los no mundo dos fatos, mundo seguido do mundo jurídico, que é parte dele ${ }^{51}$.

Fato ${ }^{52}$, então, é tudo aquilo ocorrido no mundo no passado, no presente e no futuro, o que deve ser distinguido daquilo que é mundo jurídico e a falta desta distinção ocasiona erros por parte dos aplicadores do direito.

Aponta o autor que é essencial para o estudo jurídico que sejam considerados: a elaboração da norma (fato político); a regra jurídica (fato criador do mundo jurídico); o suporte fático a que se refere (em abstrato); a incidência quando o suporte fático ocorre (em concreto); e o fato jurídico resultante e a eficácia deste fato jurídico ${ }^{53}$. Em outras palavras, o fato jurídico, nesta teoria, necessita de uma norma que incida sobre um suporte fático, resultando uma eficácia que será jurídica ${ }^{54}$.

A eficácia jurídica, então, é aquilo que é produzido no mundo do direito, em razão dos fatos jurídicos, não sendo o suporte fático que corresponde a eficácia. Os elementos do suporte fático são pressupostos do fato jurídico que, por sua vez, entra no mundo jurídico mediante a incidência da regra jurídica55.

51 MIRANDA, Pontes de. Tratado de direito privado - Tomo I (vol. 1). Introdução Pessoas Físicas e Jurídicas. $2^{\mathrm{a}}$ ed. Campinas: Bookseller, 2000. p. 49.

52 Quando se fala em fatos alude-se a algo que ocorreu, ou ocorre, ou vai ocorrer. O mundo mesmo, em que vemos acontecerem os fatos, é a soma de todos os fatos que ocorreram e o campo em que os fatos futuros vão se dar. Por isso mesmo só se vê o fato como novum no mundo. Temos, porém, no trato do direito, que discernir o mundo jurídico e o que, no mundo, não é mundo jurídico. Por falta de atenção aos dois mundos muitos erros se cometem e, o que é mais grave, se priva a inteligência humana de entender, intuir e dominar o direito. MIRANDA, Pontes de. Tratado de direito privado - Tomo I (vol. 1). Introdução Pessoas Físicas e Jurídicas. 2a ed. Campinas: Bookseller, 2000. p. 49.

53 MIRANDA, Pontes de. Tratado de direito privado - Tomo I (vol. 1). Introdução Pessoas Físicas e Jurídicas. $2^{\mathrm{a}}$ ed. Campinas: Bookseller, 2000. p. 50.

54 O direito, com a dose de elemento estabilizador que o caracteriza, ou promete que o que é, juridicamente, continuará a ser, ou que produzirá tais e tais efeitos. Ou o que é continua, até que produza os efeitos; ou continua de ser e de produzir. Também acode ele àqueles casos futuros, em que ocorrem mudanças, e diz quais as consequências e os efeitos. MIRANDA, Pontes de. Tratado de direito privado - Tomo I (vol. 1). Introdução Pessoas Físicas e Jurídicas. 2a ed. Campinas: Bookseller, 2000. p. 50.

55 MIRANDA, Pontes de. Tratado de direito privado - Tomo I (vol. 1). Introdução Pessoas Físicas e Jurídicas. $2^{a}$ ed. Campinas: Bookseller, 2000. p. 50. 
BRANDÃO, Paulo de Tarso; ZANTUT, Loren Tazioli Engelbrecht. A tirania do pensamento como um dilema democrático. Revista Eletrônica Direito e Política, Programa de Pós-Graduação Stricto Sensu em Ciência Jurídica da UNIVALI, Itajaí, v.13, n.3, $3^{\circ}$ quadrimestre de 2018. Disponível em: www.univali.br/direitoepolitica - ISSN 1980-7791

Imperioso entender a acepção de mundo e de fato para a teoria abordada. Neste sentido, para Pontes de Miranda ${ }^{56}$ todo fato é uma mudança no mundo, tendo em vista que o mundo é composto de fatos, os quais são renovados constantemente. Assim, "para nosso uso, fazemos modelos de fatos, inclusive de fatos jurídicos, para que o quadro jurídico descreva o mundo jurídico, engastando-o no mundo total".

Os fatos no mundo jurídico interessam ou não ao direito e, se interessam, enquadram-se no subconjunto do mundo denominado mundo jurídico, tornandose fatos jurídicos, pela incidência das regras jurídicas. É possível que alguns fatos entrem "duas ou mais vezes, de modo que a um fato do mundo corresponda a dois ou mais fatos jurídicos ${ }^{57 " .}$

Para que os fatos sejam jurídicos, é necessário que haja uma regra jurídica abstrata que incida ${ }^{58}$ sobre os fatos por ela abstratamente previstos. Pontes de Miranda exemplifica com a figura de uma prancha da máquina de impressão, incidindo sobre fatos que se passam no mundo, posto que aí os classifique segundo discriminações conceituais. ${ }^{59}$ Em outras palavras, a incidência de uma regra jurídica é como uma prancha da máquina de impressão, que deixa sua imagem colorida em cada folha. Outra exemplificação trazida pelo autor é que a norma é uma lâmpada que emite fachos de luz e o suporte fático seria aquele objeto sobre o qual recai esse facho, logo o objeto iluminado é o fato jurídico.

\footnotetext{
56 MIRANDA, Pontes de. Tratado de direito privado - Tomo I (vol. 1). Introdução Pessoas Físicas e Jurídicas. $2^{a}$ ed. Campinas: Bookseller, 2000. p. 51.

57 Exemplo: a morte de $A$ abre a sucessão de $A$, dissolve a comunhão de bens entre $A$ e $B$, dissolve a sociedade de A \& Companhia, exclui A da lista de sócios do Jockey Club e de professor do Instituto de Biologia ou membro do corpo diplomático. MIRANDA, Pontes de. Tratado de direito privado Tomo I (vol. 1). Introdução Pessoas Físicas e Jurídicas. 2a ed. Campinas: Bookseller, 2000. p. 52.

58 À incidência da regra jurídica tem-se chamado respeitabilidade. [...] A incidência da lei independe da sua aplicação; sem aqui trazermos à balha que os homens mais respeitam do que desrespeitam as leis, ou que as sanções são menos frequentes que as observâncias, porque, então, então, estaríamos no plano fático (físico) da sociologia do direito, em vez de mantermos no plano lógico da teoria geral do direito. MIRANDA, Pontes de. Tratado de direito privado - Tomo I (vol. 1). Introdução Pessoas Físicas e Jurídicas. 2a ed. Campinas: Bookseller, 2000. p. 57.

59 Só excepcionalmente a lei cogita de um só caso, sem que esse caso seja, sozinho, a sua classe. MIRANDA, Pontes de. Tratado de direito privado - Tomo I (vol. 1). Introdução Pessoas Físicas e Jurídicas. $2^{\mathrm{a}}$ ed. Campinas: Bookseller, 2000. p. 52.
} 
BRANDÃO, Paulo de Tarso; ZANTUT, Loren Tazioli Engelbrecht. A tirania do pensamento como um dilema democrático. Revista Eletrônica Direito e Política, Programa de Pós-Graduação Stricto Sensu em Ciência Jurídica da UNIVALI, Itajaí, v.13, n.3, $3^{\circ}$ quadrimestre de 2018. Disponível em: www.univali.br/direitoepolitica - ISSN 1980-7791

Conclui o autor que é essencial à lei colorir os fatos ${ }^{60}$, tornando-os do mundo jurídico e determinando-Ihes os efeitos, isto é, sua eficácia.

A incidência das regras jurídicas dá-se sobre todos os casos atingíveis por elas, pois as regras são de conteúdo determinado e não poderia deixar a sua incidência de forma arbitrária ${ }^{61 .}$

Por fim, ponto essencial da teoria da norma jurídica de Pontes de Miranda ${ }^{62}$ para esta pesquisa é a eficácia da lei e do fato jurídico. Para ele, a incidência da regra é a sua eficácia e a do fato jurídico é a juridicização das consequências dele, em razão da incidência. Distingue-se, então, as eficácias como: eficácia "legal" (da lei), eficácia nomológica (da regra jurídica) e a eficácia jurídica ${ }^{63}$ (mera irradiação de efeitos dos fatos jurídicos).

Em suma, Pontes de Miranda diz que um fato se torna jurídico (se "juridiciza") quando uma norma de incidência encontra um "suporte fático suficiente". Logo, a lei ao incidir sobre o suporte fático faz surgir um fato jurídico. Assim, um fato do mundo (fenomenológico) sem uma lei que o regule não será jamais jurídico. Uma lei enquanto não encontrar um fato que corresponda ao seu enunciado também não tem qualquer efeito jurídico. Constata-se, nesta linha, que é necessária a relação de incidência para que haja um fato que interesse ao Direito.

Observa-se, a seguir, quais são os efeitos das decisões na Ação Civil Pública e da Ação Direta de Inconstitucionalidade e, com base na teoria da incidência da norma jurídica de Pontes de Miranda, ora apresentada.

\footnotetext{
60 [...] toda prova de direito é prova de fatos que antecederam a ela, fato sobre os quais a regra jurídica incidiu, e da regra jurídica, escrita ou não escrita, como fato. MIRANDA, Pontes de. Tratado de direito privado - Tomo I (vol. 1). Introdução Pessoas Físicas e Jurídicas. 2a ed. Campinas: Bookseller, 2000. p. 54.

61 MIRANDA, Pontes de. Tratado de direito privado - Tomo I (vol. 1). Introdução Pessoas Físicas e Jurídicas. $2^{\mathrm{a}}$ ed. Campinas: Bookseller, 2000. p. 61.

62 MIRANDA, Pontes de. Tratado de direito privado - Tomo I (vol. 1). Introdução Pessoas Físicas e Jurídicas. $2^{\mathrm{a}}$ ed. Campinas: Bookseller, 2000. p. 62.

63 A eficácia jurídica provém da juridiciação dos fatos e, os fatos que a regra jurídica se refere vão ditar o dado fático, o suporte fático, da regra jurídica. MIRANDA, Pontes de. Tratado de direito privado - Tomo I (vol. 1). Introdução Pessoas Físicas e Jurídicas. 2a ed. Campinas: Bookseller, 2000. p. 63.
} 
BRANDÃO, Paulo de Tarso; ZANTUT, Loren Tazioli Engelbrecht. A tirania do pensamento como um dilema democrático. Revista Eletrônica Direito e Política, Programa de Pós-Graduação Stricto Sensu em Ciência Jurídica da UNIVALI, Itajaí, v.13, n.3, $3^{\circ}$ quadrimestre de 2018. Disponível em: www.univali.br/direitoepolitica - ISSN 1980-7791

\section{OS EFEITOS DA DECISÃO NA AÇÃO CIVIL PÚBLICA (EM FACE AO EFEITO ERGA OMNES) E NA AÇÃO DIRETA DE INCONSTITUCIONALIDADE}

Antes de adentrar na análise referente a teoria acima disposta, colhe-se da doutrina algumas conceituações basilares.

Os efeitos da decisão que declara a inconstitucionalidade de leis ou atos normativos no controle judicial difuso pode ter efeitos ex tunc (retroage desde a criação da norma ou do ato), quando entre as partes do processo ou ex nunc (não retroage), tratando-se de demais envolvidos ou interessados ${ }^{64}$

Posto isso, face à eficácia erga omnes das sentenças em ACP, busca-se esclarecer quais os reflexos da decisão no controle difuso de constitucionalidade em sede de ACP.

Resume Ferreira Filho que "[...] o controle incidental tem efeito apenas para as partes litigantes. A decisão que afasta o ato inconstitucional não beneficia a quem não for parte da demanda [...] É o chamado efeito particular ou inter partes ${ }^{65 " .}$ Já o efeito do controle principal é erga omnes "eliminando para o futuro e de vez qualquer possibilidade de aplicação do ato reconhecido inconstitucional ${ }^{66 "}$.

Para a doutrina e jurisprudência ${ }^{67}$, não há impeditivo aos legitimados para a propositura de ACP pleitearem, de maneira incidental, a inconstitucionalidade de leis ou atos normativos.

\footnotetext{
64 MORAES, Alexandre de. Direito Constitucional. 30. ed. São Paulo: Editora Atlas S.a., 2014. p. $739 / 740$.

65 FerReirA FILHO, Manoel Gonçalves. Curso de direito constitucional. 37a ed. São Pualo: Saraiva, 2011. p. 65

66 FERREIRA FILHO, Manoel Gonçalves. Curso de direito constitucional. 37a ed. São Pualo: Saraiva, 2011. p. 65

67 Se, contudo, o ajuizamento da ação civil pública visar, não à apreciação da validade constitucional de lei em tese, mas objetivar o julgamento de uma específica e concreta relação jurídica, aí, então, tornar-se-á lícito promover, incidenter tantum, o controle difuso de constitucionalidade de qualquer ato emanado do poder público. (...) É por essa razão que o magistério jurisprudencial dos tribunais - inclusive o do STF (Rcl 554/MG, rel. min. Maurício Corrêa - Rcl 611/PE, rel. min. Sydney Sanches, v.g.) - tem reconhecido a legitimidade da utilização da ação civil pública como instrumento idôneo de fiscalização incidental de constitucionalidade, desde que, nesse processo coletivo, a controvérsia constitucional, longe de identificar-se como objeto único da demanda, qualifique-se como simples questão prejudicial, indispensável à resolução do litígio
} 
BRANDÃO, Paulo de Tarso; ZANTUT, Loren Tazioli Engelbrecht. A tirania do pensamento como um dilema democrático. Revista Eletrônica Direito e Política, Programa de Pós-Graduação Stricto Sensu em Ciência Jurídica da UNIVALI, Itajaí, v.13, n.3, $3^{\circ}$ quadrimestre de 2018. Disponível em: www.univali.br/direitoepolitica - ISSN 1980-7791

Exemplifica Moraes:

O Ministério Público ajuíza ação civil pública, em defesa do patrimônio público, para a anulação de uma licitação baseada em lei municipal incompatível com o art. 37 da Constituição Federal. O Juiz ou Tribunal - CF, art. 97 - poderão declarar, no caso concreto, a inconstitucionalidade da citada lei municipal, e anular a licitação objeto da ação civil pública, sempre com efeitos somente para as partes e naquele caso concreto).

No entanto, erroneamente tem sido afirmado que caso a decisão expedida por Juiz ou Tribunal, declarando a inconstitucionalidade de leis ou atos normativos ocorrer em ACP e gerar efeitos erga omnes, haverá usurpação de competência do Supremo Tribunal Federal, vez ser este o único competente para controle concentrada de constitucionalidade, hipótese que ensejaria efeitos para todos ${ }^{68}$.

É recorrente encontrar-se opinião no sentido de por vezes são propostas ações civis públicas que visam, de maneira desconectada de seu verdadeiro litígio, declarar a inconstitucionalidade de um ou mais textos legais, buscando que, caso declarada a inconstitucionalidade dessas normativas, não mais sejam aptas a serem aplicadas naquela área de competência abrangida pelo tomador da decisão69.

Arruda leciona que:

Ora, se se pretende que determinados textos não possam vir a ser aplicados, dentro de uma dada área de jurisdição, disto se segue tratar-se efetivamente de declaração in abstracto,

principal (...). [RE 411.156, rel. min. Celso de Mello, dec. monocrática, j. 19-11-2009, DJE de 312-2009.]

${ }^{68}$ Controle de constitucionalidade de lei: convivência dos sistemas no STF. No STF - que acumula o monopólio do controle concentrado e direto da constitucionalidade de normas federais e estaduais com a função de órgão de cúpula do sistema paralelo de controle difuso -, é de sustar-se a decisão da arguição incidente de ilegitimidade constitucional do mesmo ato normativo pendente da decisão do pedido de medida cautelar em ação direta. [Pet 2.066 AgR-QO, rel. min. Sepúlveda Pertence, j. 2-8-2000, P, DJ de 28-2-2003.]

${ }^{69}$ ALVIM, Arruda. A declaração concentrada de inconstitucionalidade pelo STF impõe limites à ação civil pública e ao Código de Defesa do Consumidor. In: MILARÉ, Edis (Coord.). Ação Civil Pública Lei 7.347/85- Reminiscências e Reflexões após dez anos de aplicação. São Paulo: Revista dos Tribunais, 1995. p. 159/162. 
BRANDÃO, Paulo de Tarso; ZANTUT, Loren Tazioli Engelbrecht. A tirania do pensamento como um dilema democrático. Revista Eletrônica Direito e Política, Programa de Pós-Graduação Stricto Sensu em Ciência Jurídica da UNIVALI, Itajaí, v.13, n.3, $3^{\circ}$ quadrimestre de 2018. Disponível em: www.univali.br/direitoepolitica - ISSN 1980-7791

da inconstitucionalidade, ainda que possa ter sido nominado de declaração incidenter tantum ${ }^{70}$.

[...] por tudo o que foi dito, afigura-se que inconstitucionalidade levantada em ação civil pública, como pretenso fundamento para a pretensão, mas em que, real e efetivamente 0 que persiga seja a própria inconstitucionalidade, é arguição incompatível com essa ação por indicar usurpação da competência do Supremo Tribunal Federal.

Conclui-se que, conforme expõe Moraes $^{71}$, o que os julgado e parte majoritária da doutrina visa é evitar que a Ação Civil Pública sirva de sucedâneo de ADI, de forma a retirar do STF o controle concentrado de constitucionalidade das leis e atos normativos federais e estaduais face a Constituição Federal. Para o autor: "essa vedação aplica-se quando os efeitos da decisão da ação civil pública forem de eficácia erga omnes, independentemente de tratar-se de interesses difusos, coletivos e individual homogêneo.

A exemplificar o disposto, caso notório no Brasil diz respeito a declaração de inconstitucionalidade da Taxa de Iluminação Pública (TIP), em controle difuso ${ }^{72}$.

\footnotetext{
70 ALVIM, Arruda. A declaração concentrada de inconstitucionalidade pelo STF impõe limites à ação civil pública e ao Código de Defesa do Consumidor. In: MILARÉ, Edis (Coord.). Ação Civil Pública Lei 7.347/85- Reminiscências e Reflexões após dez anos de aplicação. São Paulo: Revista dos Tribunais, 1995. p. 159/162.

71 MORAES, Alexandre de. Direito Constitucional. 30. ed. São Paulo: Editora Atlas S.a., 2014. p. 742.

72 AÇÃO DECLARATÓRIA DE INEXISTÊNCIA DE RELAÇÃO JURÍDICO-TRIBUTÁRIA - TAXA DE ILUMINAÇÃO PÚBLICA - EXTINÇÃO - SENTENÇA CIVIL PROLATADA EM AÇÃO CIVIL PÚBLICA EFEITO ERGA OMNES - EXEGESE - INCIDENTE DE INCONSTITUCIONALIDADE - EFEITO ENTRE AS PARTES - RETORNO DOS AUTOS À ORIGEM - DESNECESIDADE DIANTE DO ART. 515, § 30, DO CPC - INTELIGÊNCIA DO PARÁGRAFO ÚNICO DO ART. 481 DO MESMO DIPLOMA INCONSTITUCIONALIDADE RECONHECIDA - COMPENSAÇÃO TRIBUTÁRIA - NÃO CABIMENTO PAGAMENTO DOS VALORES INDEVIDOS - PEDIDO IMPLÍCITO - PRESCRIÇÃO QÜINQÜENAL APLICAÇÃO DA TAXA SELIC A PARTIR DO ADVENTO DO CÓDIGO CIVIL DE 2002 - HONORÁRIOS ADVOCATÍCIOS EXCLUSIVAMENTE NO TOCANTE À FASE DE EXECUÇÃO - EXCLUSÃO DAS CENTRAIS ELÉTRICAS DE SANTA CATARINA S/A DA RELAÇÃO JURÍDICO-PROCESSUAL - ISENÇÃO DE CUSTAS DO ENTE PÚBLICO - PROVIMENTO PARCIAL DO APELO. Admissível a possibilidade de argüição de inconstitucionalidade em ação civil pública, desde que incidental e que trate de questão prejudicial e fundamente o pedido principal. Neste caso, a sentença que reconhecer a inconstitucionalidade não terá efeito erga omnes, este reservado à sentença civil prolatada naquela ação (art. 16 da Lei n. 7.347/85), mas tão-somente entre partes, porque no tocante ao controle difuso há necessidade de resolução suspensiva da Assembléia Legislativa. [...] (TJSC, Apelação Cível n. 2003.014739-0, de São José, rel. Des. Francisco Oliveira Filho, Segunda Câmara de Direito Público, j. 17-11-2003).
} 
BRANDÃO, Paulo de Tarso; ZANTUT, Loren Tazioli Engelbrecht. A tirania do pensamento como um dilema democrático. Revista Eletrônica Direito e Política, Programa de Pós-Graduação Stricto Sensu em Ciência Jurídica da UNIVALI, Itajaí, v.13, n.3, $3^{\circ}$ quadrimestre de 2018. Disponível em: www.univali.br/direitoepolitica - ISSN 1980-7791

Usa-se aqui a teoria de Pontes de Miranda para demonstrar e exemplificar o erro das afirmações acima por desconsiderar qual dos termos da relação de incidência que é afastado pela decisão judicial proferida em Ação Civil Pública ou em Ação Direta de Inconstitucionalidade.

Necessário se faz, inicialmente, analisar em qual a natureza da decisão de uma e outra.

$\mathrm{Na}$ ação civil pública - como em qualquer ação em que a inconstitucionalidade é reconhecida incidentemente - o juiz não se pronunciará sobre se a norma (em abstrato) é ou não inconstitucional, mas se ela é capaz prima facie de sustentar uma relação jurídica. Logo, neste caso, o que o juiz analisa é se o suporte fático pode ou não pode existir diante de uma contradição constitucional, ou seja, toda a abordagem recai sobre o suporte fático (em concreto). Mesmo que seja recorrente também os juízes em suas decisões "declararem" a lei inconstitucional, na essência eles somente desconstituem a relação fática (o suporte fático). A lei continuará existindo no mundo jurídico.

$\mathrm{Na}$ ação direta de inconstitucionalidade o Tribunal competente retira do mundo jurídico a própria norma, sem se preocupar com as eventuais relações fáticas que estariam subsumidas à lei inconstitucional. Ocorre, então, a análise em abstrato da validade da norma.

Em resumo, na ação civil pública, ainda que com caráter erga ornes, ao juiz incumbe a análise de se a relação prima facie (in)existe e, ainda que esta não exista, a norma continua existindo no mundo jurídico, vez que a análise ocorre com o fato em concreto e não da validade da norma. Mudada a condição da inconstitucionalidade a norma volta a incidir.

Já na ação direta de inconstitucionalidade o Tribunal aprecia a validade daquela norma, e, caso seja declarada inconstitucional, retira-a do mundo jurídico, o que, utilizando a metáfora apresentada por Pontes de Miranda, apaga a luz e a relação de incidência não ocorre por falta de lei. 
BRANDÃO, Paulo de Tarso; ZANTUT, Loren Tazioli Engelbrecht. A tirania do pensamento como um dilema democrático. Revista Eletrônica Direito e Política, Programa de Pós-Graduação Stricto Sensu em Ciência Jurídica da UNIVALI, Itajaí, v.13, n.3, $3^{\circ}$ quadrimestre de 2018. Disponível em: www.univali.br/direitoepolitica - ISSN 1980-7791

Para melhor compreensão, exemplifica-se a seguir. Em uma ação civil pública o juiz reconhece (com caráter erga omnes) que um determinado tributo não pode ser cobrado porque a lei não respeitou o princípio da anterioridade (anualidade) tributária previsto no artigo 150, III, "b', da Constituição Federal. O órgão arrecadador fica impedido de fazer a cobrança em relação a todas as pessoas por falta de suporte fático suficiente, mas a lei existe e basta que mude o ano tributário para que o arrecadador possa cobrar normalmente o tributo. Por sua vez, em ação direta de inconstitucionalidade se o Tribunal reconhece a inconstitucionalidade da lei pelo não respeito ao mesmo dispositivo constitucional antes referido, o órgão que tenha a pretensão de arrecadar o hipotético tributo não poderá efetuar a cobrança mesmo que ultrapassado o exercício financeiro por falta da lei excluída do sistema pelo Tribunal e para cobrar no ano seguinte deve providenciar nova lei - e, por óbvio, respeitar a anterioridade - para atingir seu objetivo.

Desta maneira, resta evidente que a Ação Civil Pública jamais será sucedâneo da Ação Direta de Constitucionalidade, atuando cada uma em seu campo próprio e gerando os efeitos que o ordenamento atribui a cada uma. Não pode a doutrina ou a jurisprudência amesquinhar o âmbito da Ação Civil Púbica passando ao largo da teoria da relação de incidência acima referida.

\section{CONSIDERAÇÕES FINAIS}

Neste artigo foi realizado levantamento bibliográfico e jurisprudencial, buscando verificar analisar a eficácia da sentença proferida em ação civil pública com pedido de inconstitucionalidade incidental e em ação direta de inconstitucionalidade, sob o prisma da teoria da norma jurídica de Pontes de Miranda.

Após o estudo de breves considerações acerca da Ação Civil Pública e da Ação Direta de Inconstitucionalidade, as matérias que são permitidas serem pleiteadas por referidos institutos, quais os legitimados e quais as formas de pleitear a inconstitucionalidade de leis em cada um desses instrumentos, foi abordada a Teoria Geral da Norma de Pontes de Miranda e a Norma de Incidência. 
BRANDÃO, Paulo de Tarso; ZANTUT, Loren Tazioli Engelbrecht. A tirania do pensamento como um dilema democrático. Revista Eletrônica Direito e Política, Programa de Pós-Graduação Stricto Sensu em Ciência Jurídica da UNIVALI, Itajaí, v.13, n.3, $3^{\circ}$ quadrimestre de 2018. Disponível em: www.univali.br/direitoepolitica - ISSN 1980-7791

Nesta etapa da pesquisa, a teoria a ser aplicada foi descrita, e, com base nela, conceituou-se regra jurídica, compreendeu-se o que é o mundo e o fato para, assim, tratar da incidência da regra jurídica.

Por fim, buscou-se reflexões acerca dos efeitos da decisão nas ações pesquisadas Ação Civil Pública com pedido incidental de declaração de inconstitucionalidade (face ao efeito erga omnes) e Ação Direta de Inconstitucionalidade.

Com o conjunto das informações, conclui-se, em síntese, que a ação civil pública, ainda que com pedido incidental de declaração de inconstitucionalidade de norma em controle difuso com eficácia erga omnes, jamais será sucedâneo de Ação Direta de Constitucionalidade ou outra ação para este fim, em razão da eficácia de suas decisões serem distintas.

Isto porque, ainda que nas condições descritas no parágrafo anterior, na Ação Civil Pública incumbe ao juiz analisar se a relação prima facie existe ou não. A norma, mesmo reconhecida a inconstitucionalidade, permanece existindo no mundo jurídico, vez que a análise ocorre com o fato em concreto (suporte fático) e não da validade da norma. A relação de incidência não ocorre por falta do suporte fático.

Na Ação Direta de Inconstitucionalidade a decisão do Tribunal competente recai sobre a validade da norma considerada em abstrato que, caso seja declarada inconstitucional, e deixa de existir no ordenamento jurídico. A relação de incidência não ocorre por falta de lei.

As presentes conclusões não têm o condão de exaurir a matéria, servindo de contribuição para posteriores reflexões sobre o assunto. 
BRANDÃO, Paulo de Tarso; ZANTUT, Loren Tazioli Engelbrecht. A tirania do pensamento como um dilema democrático. Revista Eletrônica Direito e Política, Programa de Pós-Graduação Stricto Sensu em Ciência Jurídica da UNIVALI, Itajaí, v.13, n.3, $3^{\circ}$ quadrimestre de 2018. Disponível em: www.univali.br/direitoepolitica - ISSN 1980-7791

\section{REFERÊNCIAS DAS FONTES CITADAS}

ALVIM, Arruda. A declaração concentrada de inconstitucionalidade pelo STF impõe limites à ação civil pública e ao Código de Defesa do Consumidor. In: MILARÉ, Edis (Coord.). Ação Civil Pública - Lei 7.347/85- Reminiscências e Reflexões após dez anos de aplicação. São Paulo: Revista dos Tribunais, 1995.

BRANDÃO, Paulo de Tarso. Ação Civil Pública. Florianópolis: Obra Jurídica, 1998.

BRANDÃO, Paulo de Tarso. Ações Constitucionais: "Novos" Direitos e Acesso à Justiça. 2. ed. Florianópolis: Oab/sc, 2006.

BRASIL. Constituição da República Federativa do Brasil (1988), de 05 de outubro de 1988.

BRASIL. Lei no 7.347, de 24 de julho de 1985. Disciplina a ação civil pública de responsabilidade por danos causados ao meio-ambiente, ao consumidor, a bens e direitos de valor artístico, estético, histórico, turístico e paisagístico (VETADO) e dá outras providências. Brasília, DF, 25 jul. 1985.

BRASIL. Lei no 8.078, de 11 de setembro de 1990. Dispõe Sobre a Proteção do Consumidor e dá Outras Providências. Brasília, DF.

BRASIL. Lei no 9868/1999, de 10 de novembro de 1999. Dispõe sobre o processo e julgamento da ação direta de inconstitucionalidade e da ação declaratória de constitucionalidade perante o Supremo Tribunal Federal. Brasília, DF, 10 nov. 1999.

BRASIL. SUPREMO TRIBUNAL FEDERAL. ADI 2.551 MC-QO, rel. min. Celso de Mello, j. 2-4-2003, P, DJ de 20-4-2006.

BRASIL. SUPREMO TRIBUNAL FEDERAL. ADI 91, rel. min. Sydney Sanches, j. 219-1995, P, DJ de 23-3-2001

BRASIL. SUPREMO TRIBUNAL FEDERAL. AI 217.753 AgR, rel. min. Marco Aurélio, j. 10-12-1998, 2a T, DJ de 23-4-1999.

BRASIL. SUPREMO TRIBUNAL FEDERAL. Glossário Jurídico: Ação Direta de Inconstitucionalidade. 2018. Disponível em: <http://www.stf.jus.br/portal/glossario/>. Acesso em: 15 dez. 2018.

BRASIL. SUPREMO TRIBUNAL FEDERAL. Notícias do STF: Ministro Joaquim Barbosa é o convidado do programa Aula Magna, com exibição às $21 \mathrm{~h}$. 2003.

em:

<http://noticias.stf.jus.br/portal/cms/verNoticiaDetalhe. asp?idConteudo $=61802$

>. Acesso em: 15 dez. 2018.

BRASIL. SUPREMO TRIBUNAL FEDERAL. Pet 2.066 AgR-QO, rel. min. Sepúlveda Pertence, j. 2-8-2000, P, DJ de 28-2-2003. 
BRANDÃO, Paulo de Tarso; ZANTUT, Loren Tazioli Engelbrecht. A tirania do pensamento como um dilema democrático. Revista Eletrônica Direito e Política, Programa de Pós-Graduação Stricto Sensu em Ciência Jurídica da UNIVALI, Itajaí, v.13, n.3, $3^{\circ}$ quadrimestre de 2018. Disponível em: www.univali.br/direitoepolitica - ISSN 1980-7791

BRASIL. SUPREMO TRIBUNAL FEDERAL. Rcl 8.163 AgR, rel. min. Ricardo Lewandowski, j. 3-11-2011, P, DJE de 28-11-2011

BRASIL. SUPREMO TRIBUNAL FEDERAL. RE 361.829 ED, rel. min. Ellen Gracie, j. 2-3-2010, 2a T, DJE de 19-3-2010.

BRASIL. SUPREMO TRIBUNAL FEDERAL. RE 411.156, rel. min. Celso de Mello, dec. monocrática, j. 19-11-2009, DJE de 3-12-2009.

CALDEIRA, Adriano Cesar Braz. Aspectos processuais das demandas coletivas. São Paulo: Rideel, 2006.

FERREIRA FILHO, Manoel Gonçalves. Curso de direito constitucional. $37^{a}$ ed. São Pualo: Saraiva, 2011.

MAZZILLI, Hugo Nigro. Defesa dos interesses difusos em juízo: meio ambiente, consumidor, patrimônio cultural, patrimônio público e outros interesses. 23. ed. São Paulo: Saraiva, 2010.

MIRANDA, Pontes de. Tratado de direito privado - Tomo I (vol. 1). Introdução Pessoas Físicas e Jurídicas. $2^{a}$ ed. Campinas: Bookseller, 2000.

MORAES, Alexandre de. Direito Constitucional. 30. ed. São Paulo: Editora Atlas S.a., 2014.

NERY JR., Nelson; NERY, Rosa Maria de Andrade. Código de processo civil comentado e legislação extravagante. $14^{\mathrm{a}}$ ed., São Paulo: Editora Revista dos Tribunais, 2014, p. 230-231.

SANTA CATARINA. TJSC, Apelação Cível n. 2003.014739-0, de São José, rel. Des. Francisco Oliveira Filho, Segunda Câmara de Direito Público, j. 17-11-2003.

Recebido em: 15/11/2018

Aprovado em: 17/12/2018 